\title{
UTILIZAÇÃO DE RESÍDUOS PROVENIENTES DO MILHO NA PRODUÇÃO DE CELULASES PELO FUNGO FSDE16 EM CULTIVO SEMISSÓLIDO
}

\author{
F. A. SANTOS ${ }^{1}$, A. L. C. CARDOSO ${ }^{1}$, N. T. FEITOSA ${ }^{1}$, P. M. V. de SENA e S. F. M. \\ SANTOS ${ }^{1}$ \\ ${ }^{1}$ Universidade Federal da Paraíba, Departamento de Engenharia Química \\ E-mail para contato: lipe_nino@hotmail.com
}

\begin{abstract}
RESUMO - A fermentação semissólida aplica-se ao processo de crescimento de microrganismos sobre substratos sólidos sem a presença de água livre. A principal vantagem desse processo é a possibilidade do emprego de meios de cultivo de baixo custo, como resíduos agroindustriais. O objetivo deste trabalho foi avaliar a utilização de resíduos agroindustriais como substrato para produção de enzimas celulases pelo fungo FSDE16. Os resíduos utilizados foram o sabugo e a palha de milho e o farelo de trigo. Os ensaios foram realizados em erlenmeyer de $1000 \mathrm{~mL}$ com $100 \mathrm{~g}$ de meio, em que se inoculavam os esporos e se ajustava a umidade. A temperatura de incubação e o tempo total de fermentação foram de $30^{\circ} \mathrm{C}$ e 7 dias, respectivamente. Amostras foram retiradas dos ensaios fermentativos a cada $24 \mathrm{~h}$, inclusive a $0 \mathrm{~h}$, para análise da atividade CMCase, por dosagem de açúcares redutores liberados da reação do extrato enzimático com soluções de CMC 4\%. A atividade CMCase (endoglucanase) obtida com o sabugo de milho e farelo de trigo $(50 \%)$ variou de 0,12 a 7,96 U/g, sendo que a máxima atividade foi obtida com tempo de fermentação de 168 horas, enquanto para a palha de milho e farelo de trigo $(50 \%)$ a variação foi de 0,11 a $6,44 \mathrm{U} / \mathrm{g}$, com a máxima atividade obtida também a $168 \mathrm{~h}$. Para os ensaios fermentativos realizados com o sabugo e a palha de milho puros, observou-se que não houve crescimento satisfatório do microrganismo durante os sete dias de cultivo.
\end{abstract}

\section{INTRODUÇÃO}

Os trabalhos de Mussato et al. (2007) e Murugan et al. (2011) mostraram que os processos biotecnológicos microbianos atualmente são responsáveis por uma grande parcela da economia mundial, mas apesar da potencialidade do desenvolvimento dos processos enzimáticos, os custos ainda são muito elevados. Assim, uma das alternativas para minimizar este problema é o emprego de resíduos agroindustriais como substrato. Das substâncias produzidas por microrganismos as enzimas são as que mais merecem destaque, pois a produção enzimática movimenta aproximadamente 2,34 bilhões de dólares anuais no mercado internacional (Mussatto et al., 2007). Com o avanço na ciência das enzimas, os fungos vêm adquirindo um status de destaque para vários tipos de indústrias, pois os mesmo podem ser utilizados para melhorar inúmeros aspectos relacionados ao produto final (Soares et al., 2010). Conforme Stroparo et al. (2012), dentre os fungos, os filamentosos se destacam devido à sua facilidade de cultivo, por secretarem suas enzimas diretamente no meio em que se 
encontram, não necessitando de ruptura celular para sua liberação. Adicionalmente, apresentam elevados níveis de produção enzimática, com grande potencial para diversas aplicações industriais.

Os fungos são importantes pois agem na decomposição de polímeros estruturais de plantas, como celulose, hemicelulose e lignina, por meio da liberação de enzimas características, as celulases, xilanases e lignases, que são de grande importância biotecnológica devido ao potencial comercial. Segundo Sjöström (1993) e Haichar et al. (2007), as celulases atuam na degradação da celulose, que é um polissacarídeo constituído por unidades monoméricas de $\beta$-D-glucose e representam a estrutura mais abundante nos vegetais, e fazem parte da família das glicosil-hidrolases, que hidrolisam oligossacarídeos e polissacarídeos e reconhecem as ligações $\beta-1,4$ entre as moléculas de glicose.

Ultimamente toma-se como técnicas para produção de enzimas de valor agregado, o cultivo submerso e o cultivo semissólido, destas o cultivo submerso é mais citada, mas desde meados da década de 90, o cultivo semissólido vem tomando espaço entre os pesquisadores para a produção de algumas enzimas, especialmente daquelas envolvidas na degradação de polímeros vegetais complexos (Couto; Sanromán, 2005). Neste tipo de cultivo, a macromolécula estrutural serve de matriz sólida e fornece o carbono e as fontes de energia como açúcares, lipídios, proteínas e ácidos orgânicos aos microrganismos.

\section{MATERIAIS E MÉTODOS}

Microrganismo: o microrganismo utilizado nos ensaios fermentativos foi o fungo filamentoso FSDE16, cedido pelo Prof. Dr. Demetrius Antônio Machado de Araújo do Centro de Biotecnologia-UFPB, isolado do solo de descanso do cultivo de cana-de-açúcar de uma usina no estado da Paraíba, pela aluna do Programa de Pós Graduação em Biotecnologia, (Renorbio), Laís Campos Teixeira de Carvalho. O mesmo foi selecionado pela determinação do índice enzimático. O fungo foi conservado sob refrigeração, em meio BDA (batata, ágar, dextrose).

Inóculo: foi feito o repique do fungo do estoque para placas de Petri contendo meio BDA e clorafenicol $0,1 \%$. As placas contendo o meio BDA foram inoculadas com o FSDE16 e incubadas a $37^{\circ} \mathrm{C}$ por sete dias, para o crescimento do mesmo. Após o crescimento, foi feita a suspensão dos esporos, usando água destilada estéril para raspagem das placas. A suspensão de esporos foi acondicionada em tubo estéril. A quantificação da suspensão assim obtida foi feita através de contagem dos esporos em câmara de Neubauer espelhada, com auxílio do microscópio. Todo o processo foi feito em câmara de segurança biológica, a fim de evitar qualquer tipo de contaminação.

Meio de cultivo: como meio de cultivo foram utilizados a palha e o sabugo de milho e farelo de trigo. Os resíduos foram adquiridos no comércio local da cidade de João Pessoa-PB. O sabugo e palha de milho foram triturados em moinho de martelo. Após isso, foram dispostos em bandejas e encaminhados para secagem em estufa a $60^{\circ} \mathrm{C}$, por um período de aproximadamente 48 horas. Os resíduos secos foram armazenados em recipientes fechados à temperatura ambiente. 
Ensaios fermentativos: os cultivos foram feitos utilizando 50\% de cada resíduo (sabugo e palha de milho) com 50\% de farelo de trigo e também sabugo e palha de milho puros, para um total de 100 gramas de massa. Os substratos foram umedecidos com uma solução do meio líquido proposto por Mandels e Weber (1969): Ureia 0,30g/L; $\left(\mathrm{NH}_{4}\right)_{2} \mathrm{SO}_{4} 1,4 \mathrm{~g} / \mathrm{L} ; \mathrm{KH}_{2} \mathrm{PO}_{4}$ $2,0 \mathrm{~g} / \mathrm{L} ; \mathrm{CaCl}_{2} 0,30 \mathrm{~g} / \mathrm{L} ; \mathrm{MgSO}_{4} \cdot 7 \mathrm{H}_{2} \mathrm{O} 0,3 \mathrm{~g} / \mathrm{L} ; \mathrm{FeSO}_{4} \cdot 7 \mathrm{H}_{2} \mathrm{O} 5,0 \mathrm{mg} / \mathrm{L} ; \mathrm{CoCl}_{2} \cdot 6 \mathrm{H}_{2} \mathrm{O} 20 \mathrm{mg} / \mathrm{L}$; $\mathrm{MnSO}_{4} \cdot 7 \mathrm{H}_{2} \mathrm{O} 1,6 \mathrm{mg} / \mathrm{L} ; \mathrm{ZnSO}_{4} \cdot 7 \mathrm{H}_{2} \mathrm{O} 1,4 \mathrm{mg} / \mathrm{L}$; Peptona $0,75 \mathrm{~g} / \mathrm{L}$. Para o preparo dessa solução, foi necessário calcular a quantidade de líquido que seria utilizada de acordo com a umidade de cada resíduo. A Equação 1 foi utilizada para o cálculo da quantidade de líquido. O preparo da solução de Mandels e Weber foi feito com a soma das quantidades de água de cada resíduo, fazendo a devida proporção para um litro.

$$
m_{H 2 O}=\frac{\text { massa do resíduo } * \text { (umidade ideal }- \text { umidade do resíduo) }}{1-\text { umidade ideal }}
$$

Após o preparo do meio de Mandels, os resíduos foram umedecidos com a quantidade de água calculada através da Equação 1. Os resíduos já umedecidos foram dispostos em Erlenmeyer de $1000 \mathrm{~mL}$ e esterilizados em autoclave por 15 minutos e temperatura de $121^{\circ} \mathrm{C}$. Após a autoclave, os Erlenmeyer com os meios de cultivo foram deixados em temperatura ambiente para resfriar. Com os meios de cultivo já resfriados, foi feita a inoculação com os esporos previamente suspensos. $\mathrm{O}$ volume de suspensão de esporos adicionado aos meios de fermentação foi ajustado de modo a ter-se uma concentração de $10^{6}$ esporos por grama de substrato sólido. Foi necessário homogeneizá-los bem para um crescimento uniforme do fungo. A umidade inicial utilizada nos cultivos foi de $60 \%$ e a temperatura $30^{\circ} \mathrm{C}$. Todos os cultivos foram realizados em duplicata.

A cada $24 \mathrm{~h}$ de cultivo, inclusive a $0 \mathrm{~h}$, foi retirada uma amostra de aproximadamente 3 gramas de cada cultivo, para análise do $\mathrm{pH}$, umidade e atividade enzimática. A extração do complexo enzimático foi realizada adicionando-se $11 \mathrm{~mL} /$ grama de solução salina $0,9 \%(\mathrm{pH}$ 4,5) em temperatura ambiente. Após adição da solução as amostras foram homogeneizadas e deixadas em repouso por 30 minutos. Depois foram filtradas, usando papel de filtro qualitativo. $\mathrm{O}$ filtrado foi estocado em microtubos e congelado para posterior análise de atividade de CMCase.

Atividade CMCase: Para a análise da atividade enzimática CMCase, que representa a dosagem de endoglucanases, seguiu-se o protocolo da reação enzimática utilizando carboximetilcelulose (CMC) como substrato. A atividade carboximetilcelulase (CMCase) foi determinada de acordo com a metodologia padrão descrita por Ghose (1987). O método se baseia na dosagem da concentração de açúcares redutores liberados durante a degradação do substrato carboximetilcelulose (CMC). O meio reacional foi formado por $0,25 \mathrm{~mL}$ de uma solução de CMC $4 \% \mathrm{~g} / \mathrm{L}$ em tampão citrato de sódio $50 \mathrm{mM} \mathrm{pH} \mathrm{4,8} \mathrm{e} 0,25 \mathrm{~mL}$ do sobrenadante das culturas. A mistura reacional foi incubada a $50{ }^{\circ} \mathrm{C}$, durante 10 minutos. A reação enzimática foi interrompida pela adição imediata de $0,5 \mathrm{~mL}$ de DNS (ácido 3,5-dinitro salicílico). O reagente DNS, além de interromper a reação enzimática, possibilita a realização da dosagem da concentração de açúcares redutores produzidos pela ação enzimática, obtida após fervura por 5 minutos a $100^{\circ} \mathrm{C}$. O valor da atividade enzimática CMCase pôde então, ser calculado através da Equação 2: 


$$
\text { CMCase }(U / g)=\frac{(A-B) * f * d * 0,5}{0,18 * 10 * 0,25}
$$

Onde: $\mathrm{A}=$ Absorbância da amostra; $\mathrm{B}=$ Absorbância do controle da amostra; $\mathrm{f}=$ Fator de conversão da curva de calibração $(\mathrm{mg} / \mathrm{mL}) ; \mathrm{d}=$ Diluição da amostra $(\mathrm{mL} / \mathrm{g}) ; 0,5=$ Volume total do meio de reação $(\mathrm{mL}) ; 0,18=$ Fator de conversão de mg para $\mu \mathrm{mol}$ de glicose; $10=$ Tempo de reação $(\mathrm{min}) ; 0,25$ = Volume da enzima no meio de reação $(\mathrm{mL})$.

\section{RESULTADOS E DISCUSSÕES}

Uma comparação entre os cultivos e seus diferentes valores de $\mathrm{pH}$ e umidade estão relacionados na Figura 1. Os gráficos estão representados pelas médias de $\mathrm{pH}$ e umidade para cada resíduo, já que os ensaios foram realizados em duplicata.

Figura 1 - Comparação entre os valores de $\mathrm{pH}$ e umidade para os diferentes cultivos

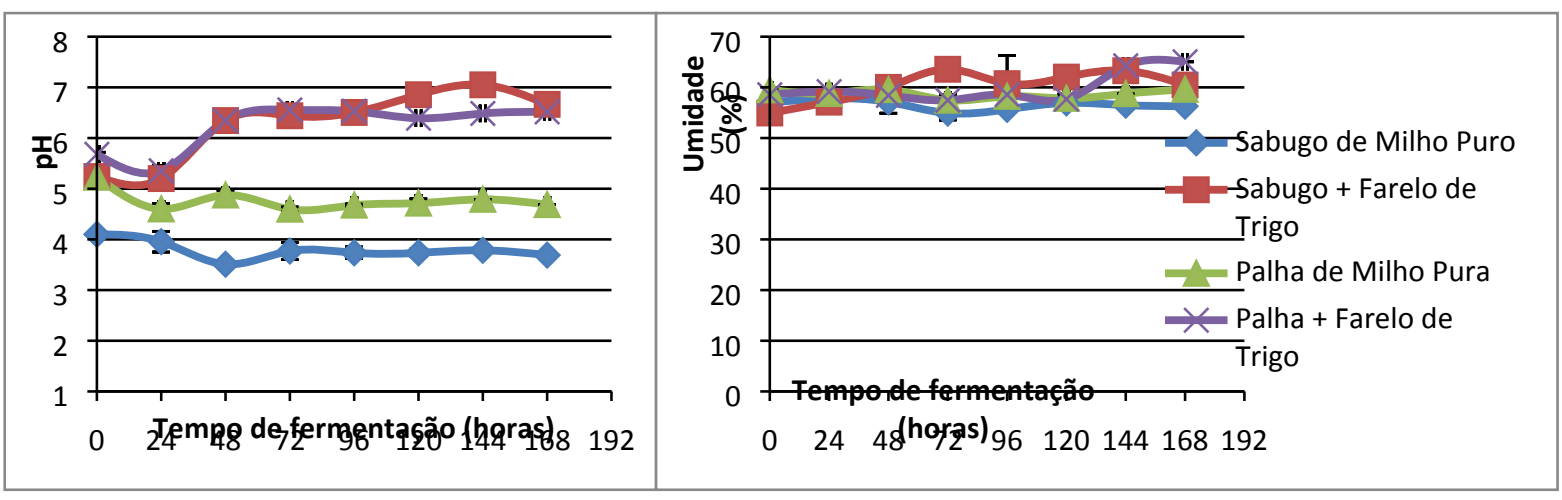

A partir deste gráfico, é possível perceber que os valores de $\mathrm{pH}$ para o cultivo utilizando o sabugo e a palha de milho puros permaneceram praticamente constantes ao longo dos sete dias, entre 3,5 e 4,1 para o sabugo e entre 4,6 e 5,2 para a palha, evidenciando que não houve crescimento do fungo. Nos cultivos utilizando o sabugo de milho com $50 \%$ de farelo de trigo, o pH variou de 5,2 até 7,05. Já para a palha de milho com $50 \%$ de farelo de trigo os valores variaram de 5,35 até 6,55. Isso comprova que houve crescimento do microrganismo nesses ensaios fermentativos. Analisando a umidade, a previsão era que os cultivos fossem realizados com $60 \%$ de umidade. Todos os cultivos estiveram na faixa $55-65 \%$, ou seja, próximos ao valor previsto. Isto pode ter ocorrido devido à perda de umidades dos meios durante o processo de esterilização.

Na Figura 2, é apresentado o resultado de atividade celulolítica CMCase em função do tempo de fermentação para o cultivo realizado com o sabugo de milho $(50 \%)$ e farelo de trigo (50\%) como também o resultado de atividade celulolítica CMCase para o cultivo realizado com a palha de milho (50\%) e farelo de trigo (50\%). As atividades estão expressas em unidade de atividade enzimática $(\mathrm{U})$ por grama de substrato $(\mathrm{g})$. Os pontos representam a média das repetições. 
Figura 2 - Atividade CMCase produzida pelo fungo FSDE16 no sabugo e na palha de milho

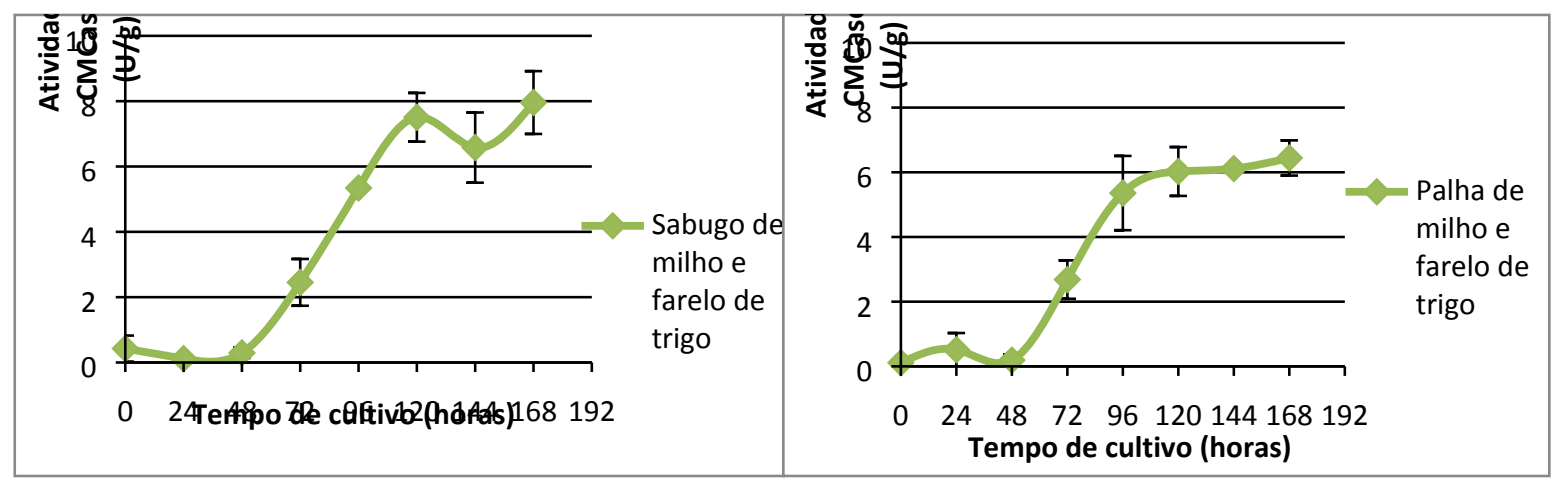

Na Figura 2, observa-se que a máxima atividade do cultivo realizado com o sabugo de milho e o farelo de trigo $(7,96 \mathrm{U} / \mathrm{g})$ foi obtida após 168 horas de fermentação na temperatura de $30^{\circ} \mathrm{C}$. Já para o cultivo realizado com a palha de milho e o farelo de trigo, observa-se que a máxima atividade $(6,44 \mathrm{U} / \mathrm{g})$ também obtida a $168 \mathrm{~h}$ e $30^{\circ} \mathrm{C}$. De acordo com Bonfim (2014), o ensaio fermentativo realizado com o fungo FSDE15 (também isolado da mesma indústria sucroalcooleira da qual o fungo FSDE16 foi isolado) utilizando farelo de trigo puro como substrato e umidade de 50\% apresentou um pico de atividade CMCase de 6,265 U/g a 96h de cultivo. Logo, o valor da atividade CMCase encontrado foi menor para o cultivo realizado com o farelo de trigo puro e FSDE15, se comparado com os cultivos realizados com farelo e resíduos do milho e FSDE16. Portanto, os resultados obtidos reforçam que os resíduos de palha e sabugo de milho utilizados apresentam potencial para a produção de enzima CMCase, bem como mostram que o fungo FSDE16 também pode ser utilizado para a obtenção das enzimas de interesse.

Para os ensaios fermentativos realizados com o sabugo e a palha de milho puros, utilizando $60 \%$ de umidade e temperatura de $30^{\circ} \mathrm{C}$, observou-se que não houve crescimento do microrganismo durante os 7 dias de cultivo. Logo, pode-se afirmar que nessa temperatura e nessa umidade esses resíduos não são bons indutores da atividade CMCase.

\section{CONCLUSÕES}

Os resultados apresentados mostram o potencial do cultivo semissólido usando o fungo filamentoso FSDE16 para produção das enzimas celulolíticas utilizando os resíduos de milho e farelo de trigo como substratos indutores.

Para o cultivo utilizando sabugo de milho e farelo de trigo obteve-se um resultado melhor do que usando a palha de milho com substrato. É necessário continuar investigando as condições de cultivo como umidade, temperatura e concentração de inóculo para aumentar os valores de produção de atividade de CMCase. O cultivo em estado sólido é uma tecnologia capaz de propor caminhos alternativos para a reutilização dos resíduos agroindustriais, diminuindo danos ambientais, bem como a valorização econômica desses rejeitos. 


\section{REFERÊNCIAS}

BONFIM, K. S., SILVA, R. K. P., CHAVES, E. J. F., CARVALHO, L. C. T., ARAÚJO, D. A. M., SANTOS, S. F. M., 2014. Comparação da síntese de celulases pelos fungos Trichoderma reesei e o FSDE15. Congresso Brasileiro de Engenharia Química.

COUTO, S.R., SANROMÁN, M.A., 2005. Application of solid-state fermentation to ligninolytic enzyme production. Biochemical Engineering Journal. 22, 211-219.

HAICHAR, F.Z., ACHOUAK, W., CHRISTEN, R., HEULIN, T., MAROL, C., MARAIS, M.F., MOUGEL, C., RANJARD, L., BALESDENT, J., BERGE, O., 2007. Identification of cellulolytic bacteria in soil by stable isotope probing. Environmental Microbiology. 9(3), 625-634.

MANDELS, M., WEBER J. Production of cellulases. Advances in Chemistry Series, 95: 391414, 1969.

MURUGAN, S., ARNOLD, D., PONGIYA, U.D., NARAYANAN, P.M., 2011. Production of Xylanase from Arthrobacter sp. MTCC 6915 Using Saw Dust As Substrate under Solid State Fermentation. Enzyme Research.

MUSSATTO, S.I., FERNANDES, M., MILAGRES, A.M.M., 2007. Enzimas: Poderosa ferramenta na indústria. Ciência Hoje. São Paulo. 41(242), 28-33.

SJÖSTRÖM, E., 1993. Wood chemistry: fundamentals and application. $2^{\text {a }}$ edição. Londres: Academic Press.

SOARES, I.A., FLORES, A.C., ZANETTIN, L., PIN, H.K., MENDONÇA, M.M., BARCELOS, R.P., TREVISOL, L. R., CARVALHO, R.D., SCHAUREN, D., ROCHA, C.L.M.C.da., 2010. Identificação do potencial amilolítico de linhagens mutantes do fungo filamentoso Aspergillus nidulans. Ciência e Tecnologia de Alimentos. 30(3), 700705.

STROPARO, E.C, BEITEL, S.M, RESENDE, J.T.V. de, KNOB, A., 2012. Seleção de fungos filamentosos e de resíduos agroindustriais para a produção de enzimas de interesse biotecnológico. Ciências Agrárias. 33(6), 2267-2278. 